\title{
Restoration of Liver Function Status in High Fat Diet Streptozotocin Induced NIDDM in Wistar Rats by Antioxidant Supplementation
}

\section{Chinaka NC ${ }^{1 *}$, Monago-Ighorodje CC $^{2}$, Chuku LC ${ }^{2}$ and Agbawo EO'}

${ }^{1}$ Department of Biochemistry, Madonna University Nigeria, Elele campus, Rivers State, Nigeria

${ }^{2}$ Department of Biochemistry, University of Port Harcourt, Choba, Port Harcourt, Rivers State, Nigeria

\begin{abstract}
The study on liver function status of high fat diet and low dose streptozotocin (HFD-STZ) induced NIDDM in Wistar rats placed on antioxidant supplementation was monitored in vitro. Some antioxidant rich substances which include some minerals and vitamins, a-lipoic acid, cinnamon powder, curcumin (Meriva $®$ ), cordyceps, resveratrol, quercetin, D-ribose-L-cysteine were assembled together in appropriate (RDA (Recommended Dietary Allowance)) proportions into corn oil and stored $4^{\circ} \mathrm{C}$ for use. Liver and kidney function test were assayed using standard analytical grade reagents and kits as well as good equipment's. Data analysis was done with SPSS version 20.0 and significant level was set at $p \leq 0.05$. A total of five groups were created and used for this study. After induction of diabetes, the treatment lasted for a total of 12 weeks, with analysis carried out at the $4^{\text {th }}, 8^{\text {th }}$ and $12^{\text {th }}$ week intervals respectively. Results obtained from assay of the functional status of the hepatocyte indicate that there was significant decrease $(p \leq$ 0.05 ) in enzyme activities of all groups with the exception of diabetic control group. Serum Aspartate Aminotransferase (AST) and serum Alanine Aminotransferase (ALT) activities of the treated groups, as well as normal control group where reduced significantly $(p \leq 0.05)$ when compared with the diabetic control group which increased constantly within the duration $\left(4^{\text {th }}\right.$ to the $12^{\text {th }}$ week) of treatment. However, significant increase $(p \leq 0.05)$ in serum Alkaline Phosphatase (ALP) activity and serum total protein level was observed in the treated groups as the duration increase with the $8^{\text {th }}$ week having the highest significant value. The results of direct and total serum bilirubin and albumin levels showed no significant difference $(p \geq 0.05)$ in all groups. Hence, the results obtained suggest that the antioxidant supplement might aid in the restoration of liver function status by reducing free radical generation and activity via increased antioxidant presence.
\end{abstract}

Keywords: Alanine; Aalkaline; Aspartate; Hepatocyte; Bilirubin; Aminotransferase

\section{Introduction}

Diabetes mellitus is a metabolic disease that affects most body systems such as the liver. The liver as a vital organ is essential in the regulation of blood glucose levels under physiological and pathological state. As a result of this function, the liver is susceptible to the effects of hyperglycaemia-induced oxidative stress, leading to free radical related liver injury [1-3].

Diabetes mellitus type 2 is known to be associated with insulin resistance in the liver, leads to hyperglycaemia as a result of distortion of glucose metabolism. Increase in insulin resistance which is associated to oxidative stress, lipid peroxidation and abnormal inflammatory signal cascade are attributed greatly to liver damage [4].

Increase in glycaemic levels, mainly caused by insulin resistance in type 2 diabetes mellitus affects the metabolism of lipids resulting in obesity related insulin resistance via accumulation of free fatty acids covering insulin receptors, a condition attributed to fatty liver. Insulin resistance resulting in increased glycaemic levels could also affect metabolism of carbohydrates and proteins. It can as well lead to nonalcoholic fatty liver disease, which has been reported to progress into non-alcoholic steatohepatitis, cirrhosis and hepatocellular carcinomas. The primary mechanism of diabetes that contributes to liver damage is the combination of increased oxidative stress and an abnormal inflammatory response, which in turn activates the transcription of proapoptotic genes and hepatocyte damage [5].

Due to the livers involvement in drug metabolism and detoxification, it becomes the most frequent organ affected in terms of drug toxicity shown in Figure 1-3. However, most important function undertaken by the liver, and the resultant production of radical species, mostly Reactive Oxygen Species (ROS) and Reactive Nitrogen Species (RNS), has been proposed as an early event of drugs hepatotoxicity and as an indicator of hepatotoxic potential [6]. Most drugs known to induce oxidative stress leading to increase mitochondria DNA damage, cellular

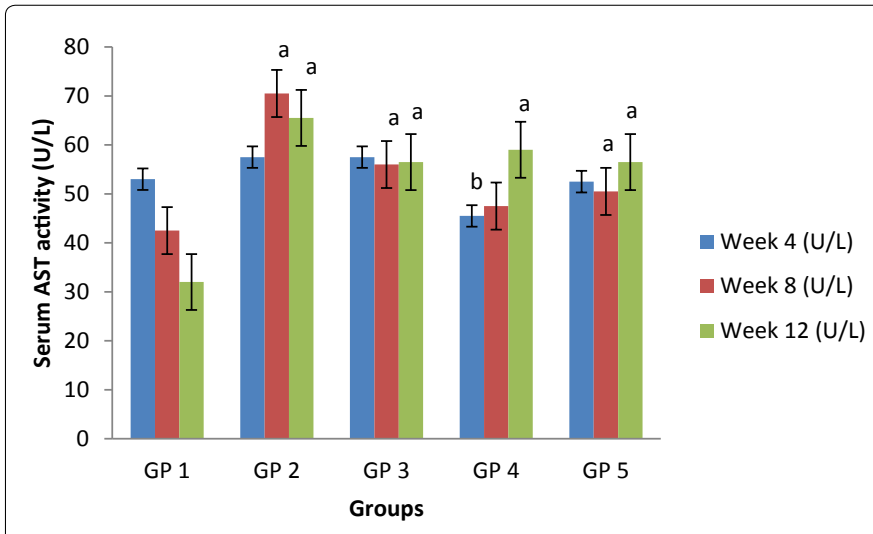

Figure 1: Serum Aspartate Amino-transaminase (AST) activity in normal and induced NIDDM albino rats administered antioxidant supplement. Data represented as Mean \pm SEM; a=significantly higher compared to the control group, $b=$ significantly lower compared to the control group.

*Corresponding author: Chinaka NC, Department of Biochemistry, Madonna University Nigeria, Elele Campus, Rivers State, Nigeria; Tel: 2348039397700 E-mail: cn_chinaka@yahoo.com

Received December 21, 2018; Accepted January 02, 2019; Published January 04, 2019

Citation: Chinaka NC, Monago-Ighorodje CC, Chuku LC, Agbawo EO (2019) Restoration of Liver Function Status in High Fat Diet Streptozotocin Induced NIDDM in Wistar Rats by Antioxidant Supplementation. Mol Biol 8: 228. doi: 10.4172/21689547.1000228

Copyright: (c) 2019 Chinaka NC, et al. This is an open-access article distributed under the terms of the Creative Commons Attribution License, which permits unrestricted use, distribution, and reproduction in any medium, provided the original author and source are credited. 


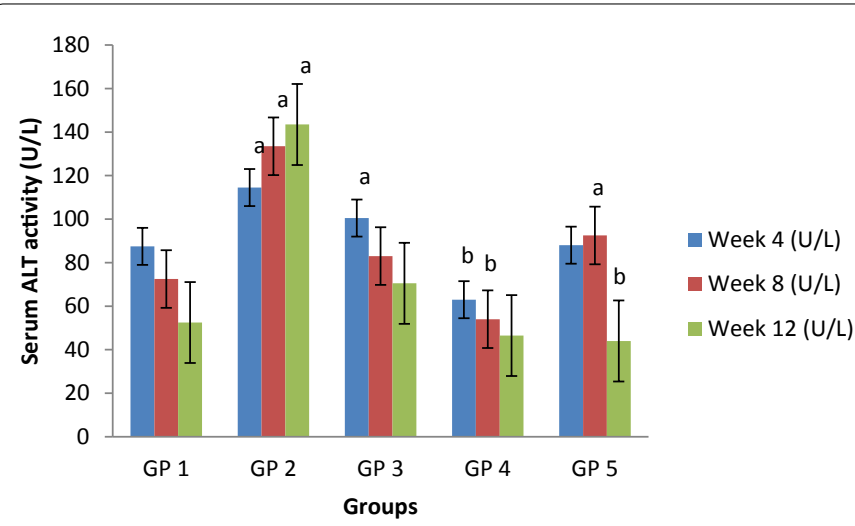

Figure 2: Serum Alanine Aminotransaminase (ALT) activity in normal and induced NIDDM albino rats administered antioxidant supplement. Data represented as Mean \pm SEM; a=significantly higher compared to the control group, $b=$ significantly lower compared to the control group.

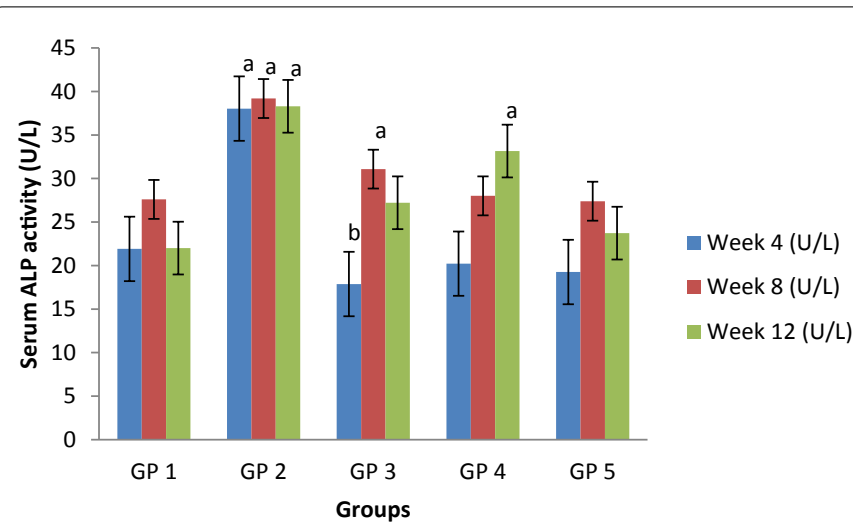

Figure 3: Serum Alkaline Phosphatase (ALP) activity in normal and induced NIDDM albino rats administered antioxidant supplement. Data represented as Mean \pm SEM; a= significantly higher compared to the control group, $b=$ significantly lower compared to the control group.

oxidants, lipid peroxidation, and depletion of antioxidants in the liver, include drugs such as anti-inflammators, anti-analgesics, anti-cancers and antidepressants. Streptozotocin and alloxan for example are also implicated in experimental designs.

Since liver injury and damage are much attributed to oxidative stress and free radical generation, the role and effect of antioxidants such as endogenous and exogenous is very crucial to this regard. The utilization of antioxidants as a curative strategy in the prevention, management and cure of liver diseases resulting from oxidative stress have been demonstrated in most in vivo and in vitro clinical studies that are animal based [7]. Hence, increased cellular levels of antioxidant in vivo has shown to balance and in fact alleviate most devastating effect of oxidative stress related cell, organ and tissue complications such as diabetes, liver cirrhosis, etc.

The study therefore aims to evaluate the restorative effect of antioxidant supplement on liver function indices of induced NIDDM in albino rats.

\section{Materials and Methods}

\section{Animal care}

Wistar rats (albino) aged 3-4 weeks (70-110 g) were purchased from the animal house of the Faculty of Pharmacy and relocated to the animal house of the Department of Biochemistry, Madonna University, Nigeria, Elele campus, Rivers State. They were kept in a well-ventilated cage with access to water and laboratory food ad libitum. The animals were distributed into five groups with 10 rats each in stainless steel cages ( $34 \times 47 \times 18 \mathrm{~cm}$ ) with soft wood shavings as bedding and maintained under normal laboratory conditions (temperature $24-28^{\circ} \mathrm{C}$, relative humidity 60\%-70\%, and 12 hour light-dark cycle). All animals used in this study were treated in conformity to the National Institute of Health (NIH) guidelines for handling laboratory animals.

\section{Preparation of high fat diet}

The high fat diet was formulated according to the method of Srinivasan [8], using growers mash $(60 \mathrm{~g} / \mathrm{kg})$, lard $(20 \mathrm{~g} / \mathrm{kg})$ and sucrose $(20 \mathrm{~g} / \mathrm{kg})$ in the ratio of 3:1:1 respectively. The diet was carefully homogenized, then fed to the animals with exception to the normal control group.

\section{Preparation of antioxidant supplement}

Recommended proportions of some antioxidant rich substances which include; vitamin A ( $14.3 \mathrm{mcg} / \mathrm{kg}$ body weight), vitamin $\mathrm{B}_{3}(0.214$ $\mathrm{mg} / \mathrm{kg}$ body weight), vitamin $B_{6}(0.03 \mathrm{mg} / \mathrm{kg}$ body weight), vitamin $\mathrm{B}_{12}(0.03 \mathrm{mg} / \mathrm{kg}$ bogy weight $)$, vitamin $\mathrm{C}(0.9 \mathrm{mg} / \mathrm{kg}$ body weight $)$ and vitamin $\mathrm{E}(0.14 \mathrm{mg} / \mathrm{kg}$ body weight); minerals like calcium $(11.4 \mathrm{mg} /$ $\mathrm{kg}$ body weight), selenium ( $0.79 \mathrm{mcg} / \mathrm{kg}$ body weight), chromium $(0.2$ $\mathrm{mcg} / \mathrm{kg}$ body weight), magnesium $(1.9 \mathrm{mg} / \mathrm{kg}$ body weight), potassium ( $0.05 \mathrm{~g} / \mathrm{kg}$ body weight) and zinc $(0.07 \mathrm{mg} / \mathrm{kg}$ body weight), $\alpha$-lipoic acid $(8.57 \mathrm{mg} / \mathrm{kg}$ body weight), cinnamon powder $(43 \mathrm{mg} / \mathrm{kg}$ body weight), curcumin [Meriva ${ }^{\oplus}$ ( $3 \mathrm{mg} / \mathrm{kg}$ body weight), cordyceps $(7.5$ $\mathrm{mg} / \mathrm{kg}$ body weight), resveratrol $(0.5 \mathrm{mg} / \mathrm{kg}$ body weight $)$, quercetin $\left(2.5 \mathrm{mg} / \mathrm{kg}\right.$ body weight), D-ribose-L-cysteine [Ribocine ${ }^{\circledR}$ ( $30 \mathrm{mg} / \mathrm{kg}$ body weight) were pulled together in corn oil and stored at $4^{\circ} \mathrm{C}$ for use as shown in Figure 4-7.

\section{Induction of type 2 diabetes mellitus}

Experimental diabetes mellitus was modeled in the animals (excluding normal control group) by feeding with high fat diet for a period of 8 weeks, after which a single dose IP injection of $35 \mathrm{mg} / \mathrm{kg}$ body weight of streptozotocin was administered.

\section{Treatment}

Treatment with standard drugs and antioxidant supplement

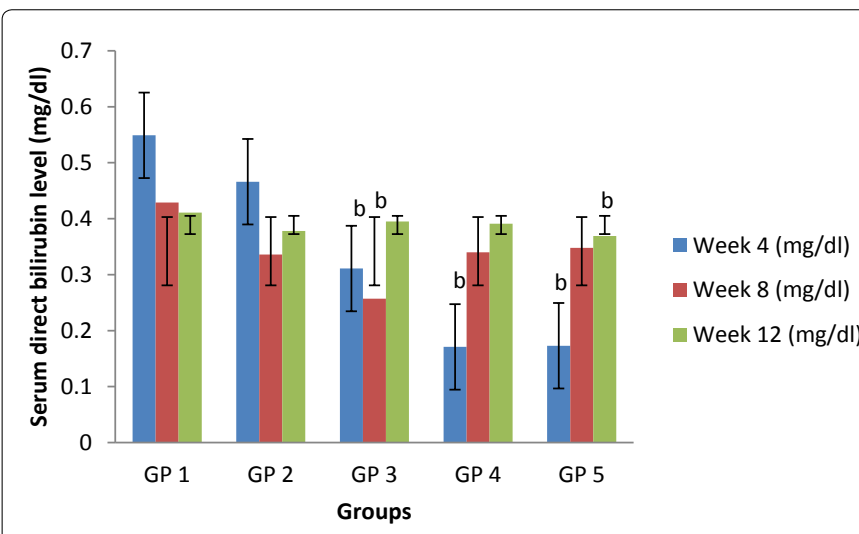

Figure 4: Serum direct bilirubin level in normal and induced NIDDM albino rats administered antioxidant supplement. Data represented as Mean \pm SEM; $a=$ significantly higher compared to the control group, $b=$ significantly lower compared to the control group. 


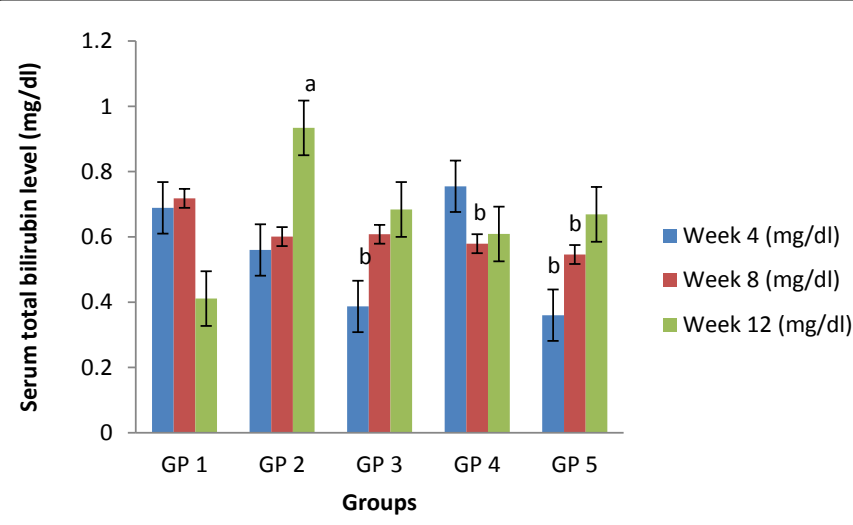

Figure 5: Serum total bilirubin level in normal and induced NIDDM albino rats administered antioxidant supplement. Data represented as Mean \pm SEM; $a=$ significantly higher compared to the control group, $b=$ significantly lower compared to the control group.

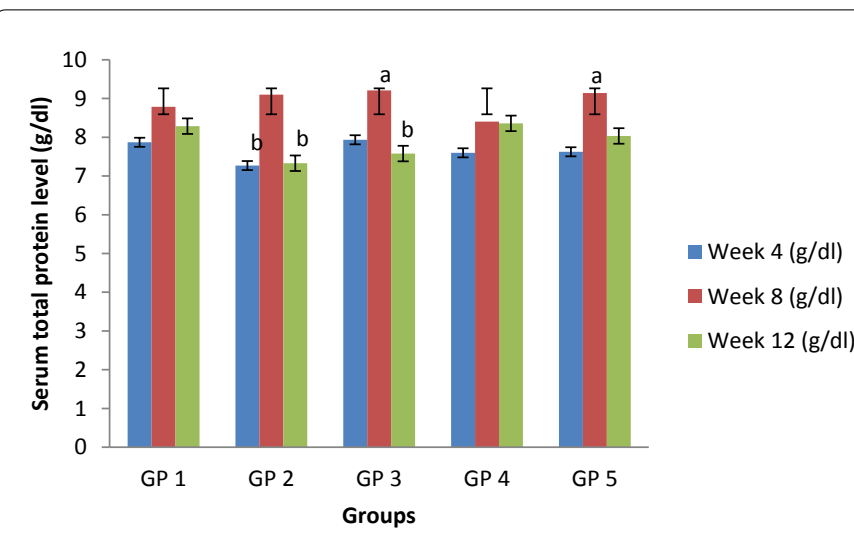

Figure 6: Serum total protein level in normal and induced NIDDM albino rats administered antioxidant supplement. Data represented as Mean \pm SEM; $a=$ significantly higher compared to the control group, $b=$ significantly lower compared to the control group.

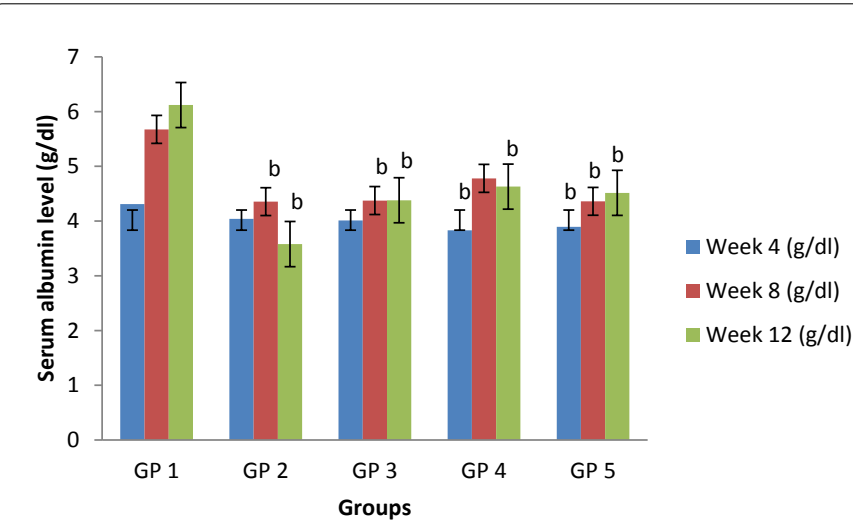

Figure 7: Serum albumin level in normal and induced NIDDM albino rats administered antioxidant supplement. Data represented as Mean \pm SEM; $a=$ significantly higher compared to the control group, $b=$ significantly lower compared to the control group.

commenced 7 days after fasting blood glucose levels were analyzed and hyperglycemia established. The treatment lasted for a period of 12 weeks with analysis carried out on the $4^{\text {th }}, 8^{\text {th }}$ and $12^{\text {th }}$ week of study as shown in Table 1.

\section{Assays}

The serum AST and ALT activities were estimated following the method of Reitman and Frankel [9] while serum ALP activity was determined using the method of Babson [10]. The serum bilirubin concentration was assayed using the method of Jendrassik and Grof [11]. Serum total protein was carried out by Biuret method as described by Rec [12]. Albumin was determined using Bromocresol Green (BCG) dye binding method of Tietz, [13].

\section{Statistical Analysis}

Data obtained from the study was analysed using the Statistical Package for Social Sciences (SPSS) version 20.0 for windows (SPSS Institute, Inc., Chicago, IL). One-way Analysis of Variance (ANOVA) was used to compare means, followed by the Tukey's test correlation.

Values were considered significant at $\mathrm{p} \leq 0.05$. Post hoc multiple comparisons for the differences between groups were established by Least Significance Differences (LSD). All the data are expressed as mean \pm Standard Error of the Mean (SEM).

\section{Results}

As shown in Table 2, after the $4^{\text {th }}$ week of treatment, there was no significant difference $(\mathrm{p} \geq 0.05)$ in the serum AST activity of the HFD/ STZ-induced diabetic control group $(57.5 \pm 1.50)$ and diabetic treated groups (actovista and cellgevity) compared to the normal control $(53.0 \pm 4.00)$. However, the diabetic group administered antioxidant supplement showed a significantly low $(\mathrm{p} \leq 0.05)$ serum AST activity. At the $8^{\text {th }}$ week of treatment, the diabetic control rats and those treated with actovista and cellgevity had significantly higher $(\mathrm{p} \leq 0.05)$ serum AST activity compared to the normal control as well as the diabeticinduced rats treated with antioxidant supplement. At the $12^{\text {th }}$ week of treatment the diabetic-induced control rats and those administered actovista and cellgevity ${ }^{\oplus}$ were observed to have significantly higher $(\mathrm{p} \leq$ $0.05)$ serum AST activity relative to the normal control.

Table 3 reveals that after the $4^{\text {th }}$ week of treatment, the serum ALT activity was significantly higher $(\mathrm{p} \leq 0.05)$ in the HFD/STZ-induced diabetic control group $(114.5 \pm 4.50)$ as well as the diabetic-induced group treated with actovista $(100.5 \pm 24.5)$ compared to the normal

\begin{tabular}{|l|c|c|c|c|c|}
\hline Group Treatment & 1 & 2 & 3 & 4 & 5 \\
\hline No. of rats per group & 10 & 10 & 10 & 10 & 10 \\
\hline Feed + water (Normal control) & + & - & - & - & - \\
\hline HFD + STZ(35 mg/kg) (Diabetic control) & - & + & - & - & - \\
\hline Diabetes + Standard drug (Actovista) & - & - & + & - & - \\
\hline Diabetes + AS (antioxidant supplement) & - & - & - & + & - \\
\hline Diabetes + Standard dietary supplement (Cellgevity) (0.72 mg/kg) & - & - & - & - & + \\
\hline $\begin{array}{l}\text { Key: + : item was administered } \\
- \text { : item was not administered }\end{array}$ & & & & \\
\hline
\end{tabular}

Table 1: Grouping and feeding illustration

\begin{tabular}{|l|c|c|c|}
\hline Groups & Week 4 (U/L) & Week 8 (U/L) & Week 12 (U/L) \\
\hline GP 1 & $53.0 \pm 4.00$ & $42.5 \pm 1.50$ & $32.0 \pm 0.00$ \\
\hline GP 2 & $57.5 \pm 1.50$ & $70.5 \pm 17.5^{\mathrm{a}}$ & $65.5 \pm 0.50^{\mathrm{a}}$ \\
\hline GP 3 & $57.5 \pm 3.50$ & $56.0 \pm 9.00^{\mathrm{a}}$ & $56.5 \pm 1.50^{\mathrm{a}}$ \\
\hline GP 4 & $45.5 \pm 0.50^{\mathrm{b}}$ & $47.5 \pm 6.50$ & $59.0 \pm 1.00^{\mathrm{a}}$ \\
\hline GP 5 & $52.5 \pm 15.5$ & $50.5 \pm 11.5^{\mathrm{a}}$ & $56.5 \pm 0.50^{\mathrm{a}}$ \\
\hline
\end{tabular}

Data represented as Mean \pm SEM; a=significantly higher compared to the control group, $b=$ significantly lower compared to the control group

Table 2: Serum Aspartate Aminotransaminase (AST) activity in normal and induced NIDDM albino rats administered antioxidant supplement. 


\begin{tabular}{|l|c|c|c|}
\hline Groups & Week 4 (U/L) & Week 8 (U/L) & Week 12 (U/L) \\
\hline GP 1 & $87.5 \pm 8.50$ & $72.5 \pm 14.5$ & $52.5 \pm 0.50$ \\
\hline GP 2 & $114.5 \pm 4.50^{\mathrm{a}}$ & $133.5 \pm 6.50^{\mathrm{a}}$ & $143.5 \pm 0.50^{\mathrm{a}}$ \\
\hline GP 3 & $100.5 \pm 24.5^{\mathrm{a}}$ & $83.0 \pm 24.0$ & $70.5 \pm 0.50$ \\
\hline GP 4 & $63.0 \pm 13.0^{\mathrm{b}}$ & $54.0 \pm 9.00^{\mathrm{b}}$ & $46.5 \pm 3.50$ \\
\hline GP 5 & $88.0 \pm 8.00$ & $92.5 \pm 31.5^{\mathrm{a}}$ & $44.0 \pm 4.00^{\mathrm{b}}$ \\
\hline
\end{tabular}

Data represented as Mean \pm SEM; a=significantly higher compared to the contro group, $b=$ significantly lower compared to the control group

Table 3: Serum Alanine Aminotransaminase (ALT) activity in normal and induced NIDDM albino rats administered antioxidant supplement.

\begin{tabular}{|l|c|c|c|}
\hline Groups & Week 4 (U/L) & Week 8 (U/L) & Week 12 (U/L) \\
\hline GP 1 & $21.92 \pm 4.05$ & $27.60 \pm 3.78$ & $22.00 \pm 0.50$ \\
\hline GP 2 & $38.03 \pm 1.60^{\mathrm{a}}$ & $39.19 \pm 0.71^{\mathrm{a}}$ & $38.29 \pm 0.29^{\mathrm{a}}$ \\
\hline GP 3 & $17.88 \pm 4.05^{\mathrm{b}}$ & $31.08 \pm 5.34^{\mathrm{a}}$ & $27.21 \pm 0.21$ \\
\hline GP 4 & $20.22 \pm 4.79$ & $28.01 \pm 9.26$ & $33.15 \pm 0.98^{\mathrm{a}}$ \\
\hline GP 5 & $19.26 \pm 2.98$ & $27.39 \pm 1.18$ & $23.73 \pm 2.68$ \\
\hline
\end{tabular}

Data represented as Mean \pm SEM; a=significantly higher compared to the control group, $b=$ significantly lower compared to the control group

Table 4: Serum alkaline phosphatase (ALP) activity in normal and induced NIDDM albinorats administered antioxidant supplement.

control group $(87.5 \pm 8.50)$ which had no significant difference with the induced group treated with cellgevity $(88.0 \pm 8.00)$. The antioxidant supplement administered to the diabetic-induced group (GP 4) showed a significantly low $(\mathrm{p} \leq 0.05)$ serum ALT activity compared to the normal control group. At the $8^{\text {th }}$ and $12^{\text {th }}$ weeks of treatment, the diabetic control rats showed significantly higher $(\mathrm{p} \leq 0.05)$ serum ALT activity compared to the normal control as well as the diabetic-induced rats administered various treatments.

As shown in Table 4 , at the $4^{\text {th }} 8^{\text {th }}$ and $12^{\text {th }}$ weeks of treatment, the HFD/STZ-induced diabetic control group $(38.03 \pm 1.60,39.19 \pm 0.71$ and $38.29 \pm 0.29)$ had significantly higher $(\mathrm{p} \leq 0.05)$ serum ALP activity compared to the normal control $(21.92 \pm 4.05,27.60 \pm 3.78$ and 22.00 $\pm 0.50)$ and the diabetic-induced groups treated with the actovista, antioxidant supplement, cellgevity ${ }^{\circ}$ respectively. However, at the $8^{\text {th }}$ and $12^{\text {th }}$ weeks of treatment, the diabetic-induced group administered actovista $(31.08 \pm 5.34)$ and antioxidant supplement (33.15 \pm 0.98$)$, showed significantly higher $(\mathrm{p} \leq 0.05)$ serum ALP activity compared to their respective normal controls $(27.60 \pm 3.78$ and $22.00 \pm 0.50)$.

Table 5 showed that after the $4^{\text {th }}$ week of treating, the serum direct bilirubin levels were significantly higher $(\mathrm{p} \leq 0.05)$ in the normal and diabetic control groups compared to the diabetic-induced groups treated with actovista, antioxidant supplement and cellgevity respectively. At the $8^{\text {th }}$ and $12^{\text {th }}$ weeks there were no significant differences $(\mathrm{p} \geq 0.05)$ in the serum direct bilirubin levels of the diabetic control group compared to the normal control as well as some the diabetic treated groups, with the exception of the groups treated with actovista and cellgevity which respectively showed a significantly low $(\mathrm{p} \leq 0.05)$ serum direct bilirubin levels.

Table 6 reveals that after the $4^{\text {th }}$ and $8^{\text {th }}$ weeks of treating the HFD/ STZ-induced diabetic rats, there was no significant difference $(p \geq 0.05)$ in the serum total bilirubin levels of the diabetic control compared to the normal control as well as the diabetic treated with antioxidant supplement and actovista respectively. Other diabetic treated groups showed a significant low $(\mathrm{p} \leq 0.05)$ levels compared to the normal and diabetic controls. At the $12^{\text {th }}$ week of treatment the diabetic control had significantly higher $(\mathrm{p} \leq 0.05)$ serum total bilirubin level compared to the normal control and diabetic treated groups.
On the $4^{\text {th }}$ and $12^{\text {th }}$ weeks, the serum total protein levels were observed to be statistically low ( $\mathrm{p} \leq 0.05$ ) in the HFD/STZ-induced diabetic control group, compared to the normal control as well as the diabetic treated groups as shown in Table 7 . At the $8^{\text {th }}$ week of treatment the diabetic treated groups (actovista and cellgevity) had a significantly high $(\mathrm{p} \leq 0.05)$ serum total protein levels relative to the controls and the antioxidant supplement groups. There was however, no significant difference $(p \geq 0.05)$ in the serum total protein levels between the diabetic group treated with actovistaon the $8^{\text {th }}$ and $12^{\text {th }}$ week respectively.

As revealed in Table 8, after four weeks of treatment, only the groups treated with antioxidant supplement and cellgevity showed a significantly low $(\mathrm{p} \leq 0.05)$ serum albumin levels compared to the normal and diabetic control groups. However, the group receiving actovista showed no significant difference $(\mathrm{p} \geq 0.05)$ when compared with the controls. After the $8^{\text {th }}$ and $12^{\text {th }}$ week of treatment, the serum albumin level in the

\begin{tabular}{|l|c|c|c|}
\hline Groups & Week 4 (mg/dL) & Week 8 (mg/dL) & Week 12 (mg/dL) \\
\hline GP 1 & $0.549 \pm 0.09$ & $0.429 \pm 0.02$ & $0.411 \pm 0.00$ \\
\hline GP 2 & $0.466 \pm 0.08$ & $0.336 \pm 0.01$ & $0.378 \pm 0.00$ \\
\hline GP 3 & $0.311 \pm 0.01^{\mathrm{b}}$ & $0.257 \pm 0.01^{\mathrm{b}}$ & $0.395 \pm 0.01$ \\
\hline GP 4 & $0.171 \pm 0.00^{\mathrm{b}}$ & $0.340 \pm 0.02$ & $0.391 \pm 0.02$ \\
\hline GP 5 & $0.173 \pm 0.01^{\mathrm{b}}$ & $0.348 \pm 0.01$ & $0.369 \pm 0.03^{\mathrm{b}}$ \\
\hline
\end{tabular}

Data represented as Mean $\pm \mathrm{SEM}$; a=significantly higher compared to the control group, $b=$ significantly lower compared to the control group

Table 5: Serum direct bilirubin level in normal and induced NIDDM albino rats administered antioxidant supplement.

\begin{tabular}{|l|c|c|c|}
\hline Groups & Week 4 (mg/dL) & Week 8 (mg/dL) & Week 12 (mg/dL) \\
\hline GP 1 & $0.689 \pm 0.08$ & $0.718 \pm 0.15$ & $0.411 \pm 0.01$ \\
\hline GP 2 & $0.560 \pm 0.02$ & $0.601 \pm 0.13$ & $0.934 \pm 0.03^{\mathrm{a}}$ \\
\hline GP 3 & $0.387 \pm 0.03^{\mathrm{b}}$ & $0.608 \pm 0.01$ & $0.684 \pm 0.02$ \\
\hline GP 4 & $0.755 \pm 0.47$ & $0.579 \pm 0.02^{\mathrm{b}}$ & $0.609 \pm 0.02$ \\
\hline GP 5 & $0.360 \pm 0.06^{\mathrm{b}}$ & $0.546 \pm 0.01^{\mathrm{b}}$ & $0.669 \pm 0.00$ \\
\hline
\end{tabular}

Data represented as Mean $\pm \mathrm{SEM}$; $a=$ significantly higher compared to the contro group, $b=$ significantly lower compared to the control group

Table 6: Serum total bilirubin level in normal and induced NIDDM albino rats administered antioxidant supplement.

\begin{tabular}{|l|c|c|c|}
\hline Groups & Week 4 (g/dL) & Week 8 (g/dL) & Week 12 (g/dL) \\
\hline GP 1 & $7.870 \pm 0.20$ & $8.785 \pm 0.57$ & $8.285 \pm 0.29$ \\
\hline GP 2 & $7.270 \pm 0.66^{\mathrm{b}}$ & $9.100 \pm 0.88$ & $7.330 \pm 0.33^{\mathrm{b}}$ \\
\hline GP 3 & $7.935 \pm 0.27$ & $9.210 \pm 0.57^{\mathrm{a}}$ & $7.580 \pm 0.08^{\mathrm{b}}$ \\
\hline GP 4 & $7.600 \pm 0.33$ & $8.405 \pm 0.38$ & $8.360 \pm 0.07$ \\
\hline GP 5 & $7.625 \pm 0.49$ & $9.140 \pm 0.21^{\mathrm{a}}$ & $8.035 \pm 0.08$ \\
\hline
\end{tabular}

Data represented as Mean $\pm \mathrm{SEM}$; $a=$ significantly higher compared to the control group, $b=$ significantly lower compared to the control group

Table 7: Serum total protein level in normal and induced NIDDM albino rats administered antioxidant supplement.

\begin{tabular}{|l|c|c|c|}
\hline Groups & Week 4 (g/dl) & Week 8 (g/dl) & Week 12 (g/dl) \\
\hline GP 1 & $4.310 \pm 0.08$ & $5.675 \pm 0.29$ & $6.120 \pm 0.02$ \\
\hline GP 2 & $4.040 \pm 0.08$ & $4.355 \pm 0.05^{\mathrm{b}}$ & $3.580 \pm 0.02^{\mathrm{b}}$ \\
\hline GP 3 & $4.010 \pm 0.40$ & $4.375 \pm 0.15^{\mathrm{b}}$ & $4.380 \pm 0.02^{\mathrm{b}}$ \\
\hline GP 4 & $3.830 \pm 0.06^{\mathrm{b}}$ & $4.780 \pm 0.19$ & $4.630 \pm 0.04^{\mathrm{b}}$ \\
\hline GP 5 & $3.895 \pm 0.14^{\mathrm{b}}$ & $4.360 \pm 0.07^{\mathrm{b}}$ & $4.515 \pm 0.13^{\mathrm{b}}$ \\
\hline
\end{tabular}

Data represented as Mean \pm SEM; a=significantly higher compared to the control group, $b=$ significantly lower compared to the control group

Table 8: Serum albumin level in normal and induced NIDDM albino rats administered antioxidant supplement. 
diabetic control and other treated groups were significantly lower $(\mathrm{p} \leq 0.05)$ compared to that of the normal control group.

\section{Discussion}

The result obtained from the assessment of liver functional status showed a significant decrease $(\mathrm{p} \leq 0.05)$ in serum enzyme activities (AST and ALT) of all groups with the exception of diabetic control group which was statistically increased. The Aspartate Aminotransferase (AST) and Alanine Aminotransferase (ALT) activities of the treated and normal control groups where reduced significantly $(\mathrm{p} \leq 0.05)$ when compared with the diabetic control group which increased constantly with duration (from $4^{\text {th }}$ to the $12^{\text {th }}$ week) especially in ALT activity. Such observation could be attributed to the ability of the antioxidant supplement to balance off the free radicals generated hence preventing peroxidation of the lipid components of the cell membrane. Disruption of membrane integrity is a common causative factor which is attributed to increased release or leakage of cellular contents such as these enzymes studied. This finding was consistent with the work of Al-Sultan [14] and Kandaswamy [15] who reported similar results on the effect antioxidants on liver markers. However, significant increase ( $\mathrm{p} \leq 0.05)$ in Alkaline Phosphatase (ALP) activity was observed in the treated groups as the duration increase with the $8^{\text {th }}$ week recording the highest significant value. Similar result was also reported by Ghanbari [16] and Kandaswamy [12]. The latter reported a rapid mobilization of liver-ALP in blood, resulting in increased serum levels at early stages of liver damage. They further reported that high serum ALP level is mostly indicative of cholestasis resulting in progressive liver disease (biliary cirrhosis). The results of direct and total bilirubin levels showed no significant difference $(p \geq 0.05)$ between the normal and diabetic control groups, with the exception of a few diabetic treated groups. The serum levels of total protein and albumin were observed to be statistically low $(\mathrm{p} \leq 0.05)$ in the diabetic control group compared to the normal control group and some treated groups, although with a few exceptions across the duration of study. The observations could be attributed to the increased presence of the various treatments over the duration of study, which previous and existing treatment regimens do not achieve under such study duration. These findings on serum total protein and serum albumin were indifferent with those of Ghanbari [16] who reported that diabetes caused a significant decrease in serum TP and albumin levels, although their levels were significantly reversed by the oral administration of Royal Jelly. The levels of serum albumin showed no significant differences between the diabetic control, normal and some diabetic treated groups (4 and 5) after the $4^{\text {th }}$ week of study. Hence, it is indicative that this study supports the findings of previous work with a few exceptions regarding duration since the studies were carried out under different study designs. The observed correlation in the results observed with those of earlier findings, is evident of the restorative effect of antioxidants in ameliorating diabetes related liver damage in relation to some type 2 anti-diabetic drugs which does not necessarily address or target oxidative stress and free radical complications.

\section{Conclusion}

Conclusively, the findings affirms the therapeutic effect of antioxidants and its supplements as a huge protective agent against oxidative stress and free radical aggravated liver disease and obesityinduced type 2 diabetes mellitus which has been reported to affect the liver by aggravating oxidative stress related inflammatory signals, insulin resistance and subsequently chronic conditions such as cirrhosis and liver damage. Therefore, the role of antioxidants as emerging future therapy is promising as an alternative source of remedy in the prevention, management and treatment of oxidative stress related diseases such as diabetes mellitus.

\section{References}

1. Al-Sultan Al (2008) Assessment of the Relationship of Hepatic Enzymes with Obesity and Insulin Resistance in Adults in Saudi Arabia. Sultan Qaboos Univ Med J 8: 185-192.

2. Babson AL (1966) Phenolphthalein monophosphate, a new substrate for alkaline phosphatise. Clin Chem 12: 482-490.

3. Bugianesi E, McCullough AJ, Marchesini G (2005) Insulin resistance: A metabolic pathway to chronic liver disease. Hepatology 42: 987-1000.

4. Ghanbari E, Nejati V, Khazaei M (2016) Improvement in Serum Biochemical Alterations and Oxidative Stress of Liver and Pancreas following Use of Royal Jelly in Streptozotocin-Induced Diabetic Rats. Cell J 18: 362-370.

5. Jendrassik L, Grof P (1938) Colorimetric Method of Determination of bilirubin Egypt. American Biochem J 297: 81-82.

6. Linares V, Alonso V, Albina ML, Belles M, Sirvent JJ, et al. (2009) Lipid peroxidation and antioxidant status in kidney and liver of rats treated with sulfasalazine. Toxicology 256: 152-156.

7. Manna P, Das J, Ghosh J, Sil PC (2010) Contribution of type 1 diabetes to rat liver dysfunction and cellular damage via activation of NOS, PARP IkappaBalpha/NF-kappaB, MAPKs, and mitochondria-dependent pathways Prophylactic role of arjunolic acid. Free Radic Biol Med 48:1465-484.

8. Mohamed J, Nazratun NAH, Zariyantey AH, Budin SB (2016) Mechanisms of Diabetes-Induced Liver Damage: The role of oxidative stress and inflammation. Sultan Qaboos Univ Med J 16: e132-e141.

9. Palsamy P, Sivakumar S, Subramanian S (2010) Resveratrol attenuates hyperglycemia-mediated oxidative stress, proinflammatory cytokines and protects hepatocytes ultrastructure in streptozotocin-nicotinamide-induced experimental diabetic rats. Chem Biol Interact 186: 200-210.

10. Rec GSCC (1972) Colorimetric method for serum Alkaline Phosphatase determination. Indian J Clin Biochem 10: 182-184.

11. Reitman S, Frankel S (1957) A colorimetric method for the determination of serum glutamic oxaloacetic and glutamic pyruvic transaminases. J Clin Pathol 28: $56-63$.

12. Selvakumar K, Bavithra S, Suganya S, Ahmad BF, Krishnamoorthy G, et al. (2013) Effect of Quercetin on Haematobiochemical and Histological Changes in the Liver of Polychlorined Biphenyls-Induced Adult Male Wistar Rats. J Mol Biomark 960125: 1-12.

13. Seven A, Guzel S, Seymen O, Civelek S, Bolayirli M, et al. (2004) Effects of vitamin $E$ supplementation on oxidative stress in streptozotocin induced diabetic rats: Investigation of liver and plasma. Yonsei Med J 45: 703-710.

14. Li S, Tan HY, Wang N, Zhang ZJ, Lao L, et al. (2015) The Role of Oxidative Stress and Antioxidants in Liver Diseases. Int J Mol Sci 16: 26087-26124.

15. Tietz Nw (1995) Clinical Guide to Laboratory Tests, Saunders WB, Philadelphia, PA. 23-28.

16. Videla LA (2009) Oxidative stress signaling underlying liver disease and hepatoprotective mechanisms. World J Hepatol 1: 72-78. 